\title{
PINS Measurements and Simulations for Stand-Off Detection of High Explosives
}

E. H. Seabury

July 2011

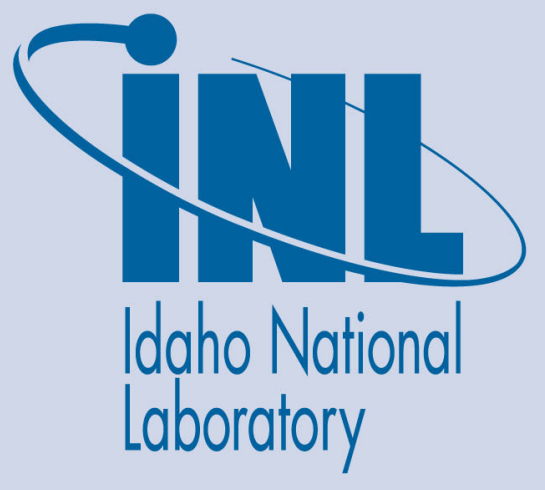

The INL is a U.S. Department of Energy National Laboratory operated by Battelle Energy Alliance 
INL/EXT-11-22803

\title{
PINS Measurements and Simulations for Stand-Off Detection of High Explosives
}

\author{
E. H. Seabury
}

July 2011

Idaho National Laboratory
Idaho Falls, Idaho 83415

http://www.inl.gov

Prepared for the

U.S. Department of Energy

Office of National Nuclear Security Administration

Under DOE Idaho Operations Office

Contract DE-AC07-05ID14517 


\title{
PINS Measurements and Simulations for Stand-Off Detection of High Explosives
}

\author{
E.H. Seabury \\ Idaho National Laboratory
}

21 July 2011

There has been some interest in the ability of Idaho National Laboratory's (INL) Portable Isotopic Neutron Spectroscopy System's (PINS) ability to detect high explosives at a distance. In order to assess the system's ability to perform this task, laboratory experiments on simulated or mock explosives and Monte Carlo simulations using MCNP on both mock and real explosives have been performed. The simulations and experiments on mock explosives have essentially identical configurations, allowing the models to be confirmed with experiment. This provides greater confidence in the simulations on real explosives without the need for experiment on live explosives.

The geometry can be seen in Figure 1 below, where a photo of the PINS system without the detector is shown configured for examining two nalgene bottles filled with simulated HMX. The detector crystal was placed in the Bismuth collimator to the left. The bottles were placed at increasing distances from the detector in 10-centimeter increments, with the zero point of the distances being the detector face.

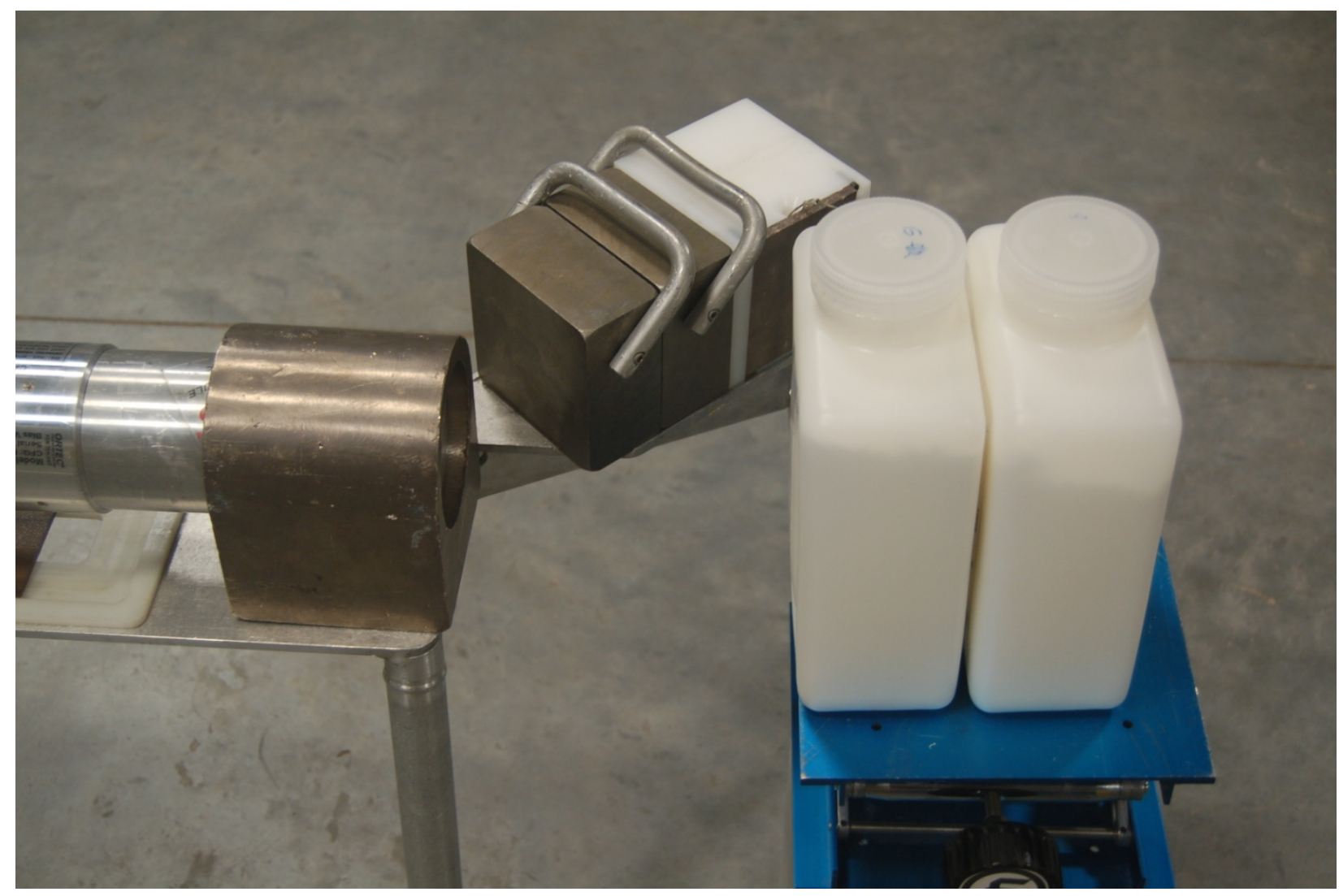

Figure 1 Configuration for laboratory measurements. 
The elemental compositions of the mock HMX and real HMX can be seen in Table 1 below. As can be seen in the table, the mock HMX has significantly lower density and nitrogen content than real $H M X$. Simulations of the real HMX therefore had a somewhat different geometry than those of the mock HMX to account for the difference in density. The HMX in the simulations consisted of a nalgenecontained cube of explosive, with a side length of $12.84 \mathrm{~cm}$.

Table 1 Comparison of real and mock HMX

\begin{tabular}{|l|l|l|l|l|l|l|}
\hline & Hydrogen \% & Carbon \% & Nitrogen \% & Oxygen \% & Sodium \% & $\begin{array}{l}\text { Density } \\
(\mathrm{g} / \mathrm{cc})\end{array}$ \\
\hline HMX & 2.7 & 16.2 & 37.8 & 43.2 & 0 & 1.89 \\
\hline Mock HMX & 2.6 & 18.0 & 18.4 & 43.2 & 17.8 & 1.1 \\
\hline
\end{tabular}

The MCNP simulations of the 4 kilograms of mock HMX are shown in Figure 2 below. The plot shows the fluence of $10.8 \mathrm{MeV}$ gamma rays from neutron capture on nitrogen as a function of the distance of the mock HMX from the zero point. The fluence was tallied in the detector crystal. As can be seen in the plot, the detection of nitrogen does not fall off as a function of distance to the fourth power, but more on the order of the distance squared for these relatively close geometries. This dependence appears to agree less as the distance is increased between the detector and the mock HMX. Figure 3 shows similar calculations for HMX where the net nitrogen counts are increased due to the higher nitrogen concentration in the real explosive compared with the mock. 


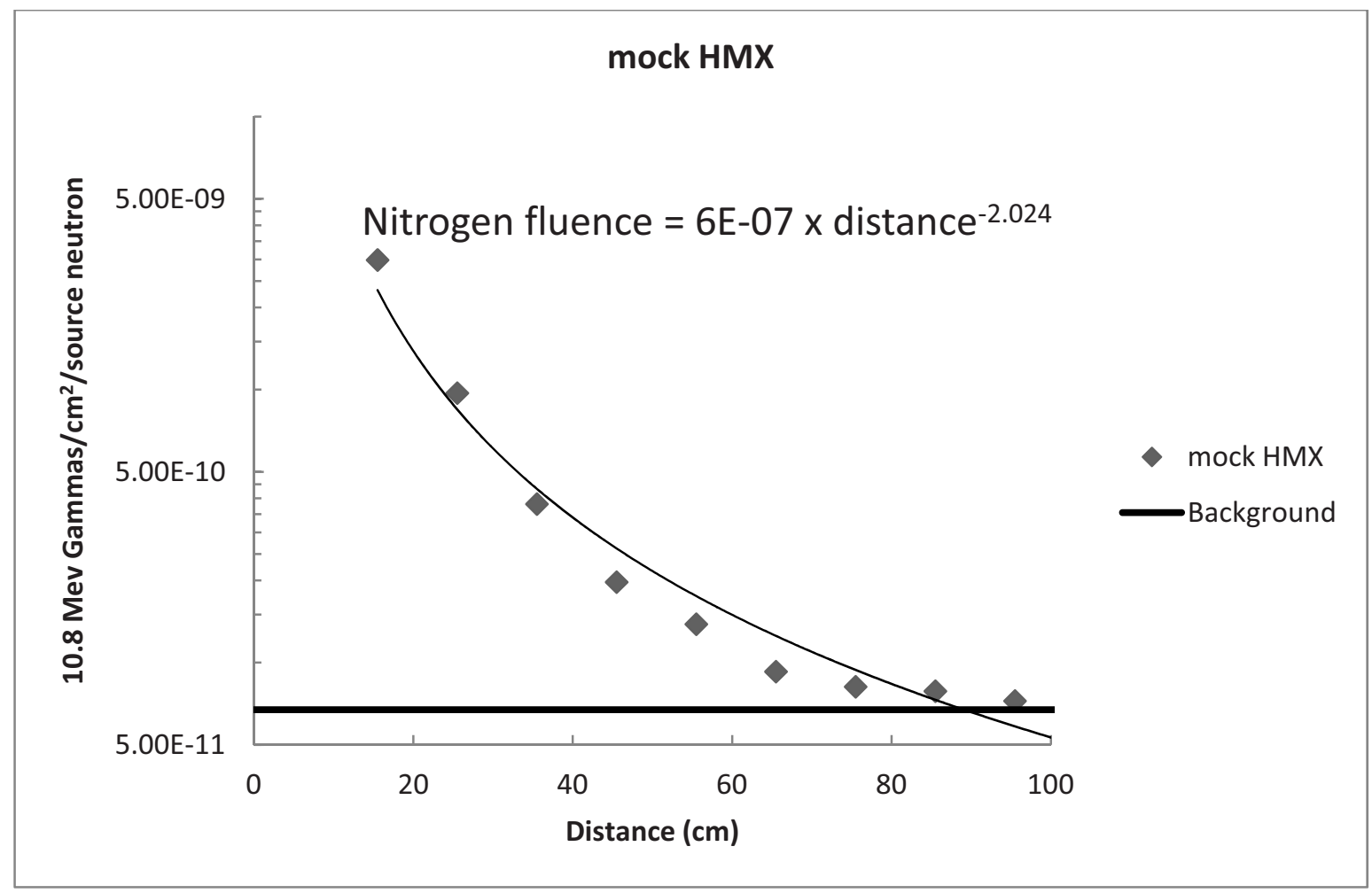

Figure 2 Simulated nitrogen gamma fluence versus distance for mock HMX

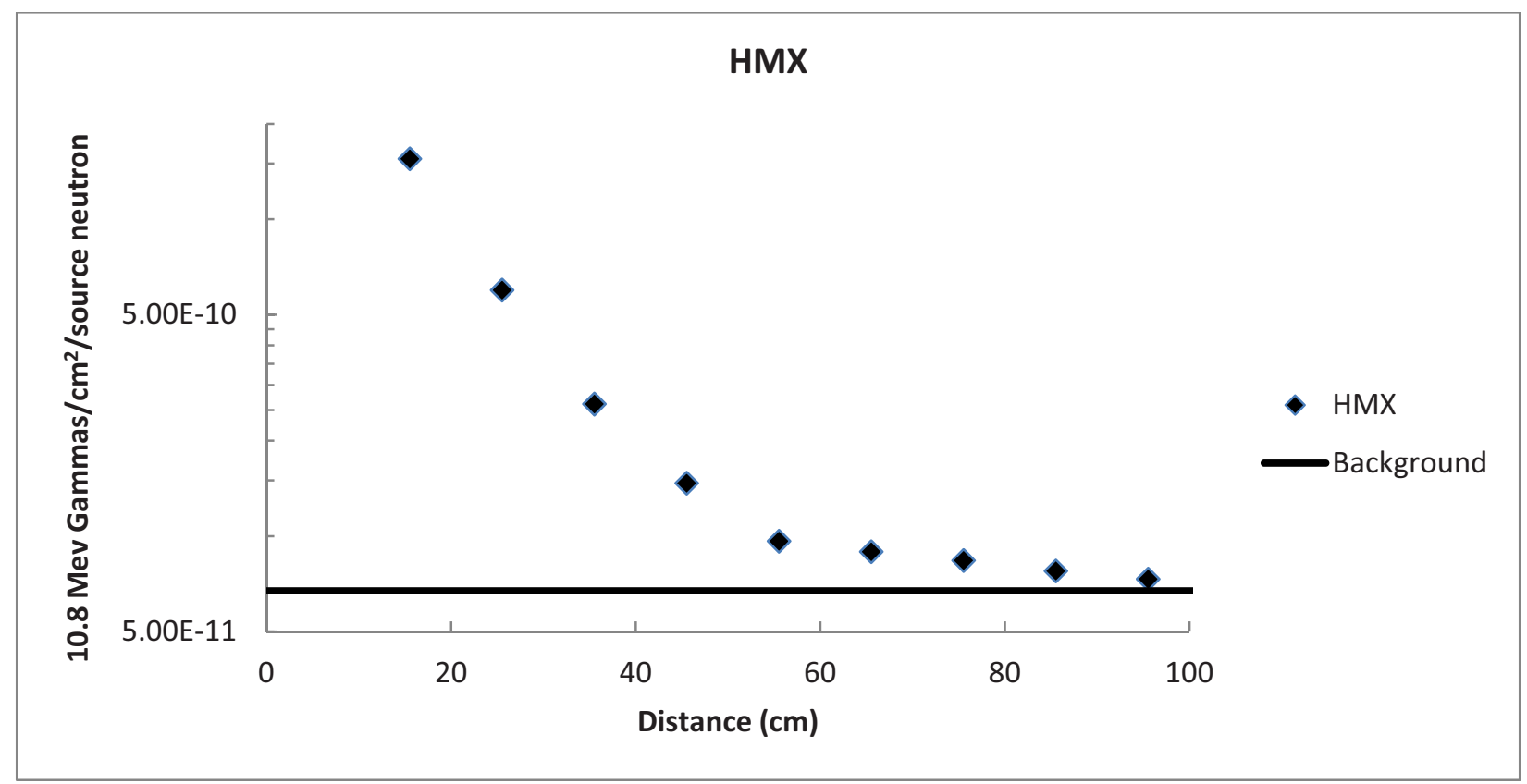

Figure 3 Simulated nitrogen gamma ray fluence versus distance for HMX 
The time to identify the mock HMX as explosives was also recorded in the laboratory measurements, at least for closer geometries where the identification time was less than approximately one hour. If we assume that the time to identify is based on the net nitrogen gamma ray count rate after background subtraction, then we can normalize the measurements with the simulation and estimate the time to identify real HMX. Figure 4 shows a plot of such an estimate as a function of distance from the zero point for the mock HMX as well as the real measured values. The same estimate is shown for the real HMX in figure 5 . After approximately $40 \mathrm{~cm}$, the measurement time to identify the HMX as explosives could be greater than 3 hours. A 12 hour measurement could be able to detect the $H M X$ at $80 \mathrm{~cm}$ and a full day could detect the HMX at 1 meter distance.

These estimates of detection time should be viewed as lower bounds given the basis for their estimate. Identification of explosives could take longer given that the PINS+ software identifies explosives largely based on the statistical probability of nitrogen detection above background. Using the net nitrogen counts above background rather than the probability of nitrogen detection above background nitrogen levels could be underestimating the necessary count time to provide adequate statistics for both the background and nitrogen gamma ray count rates.

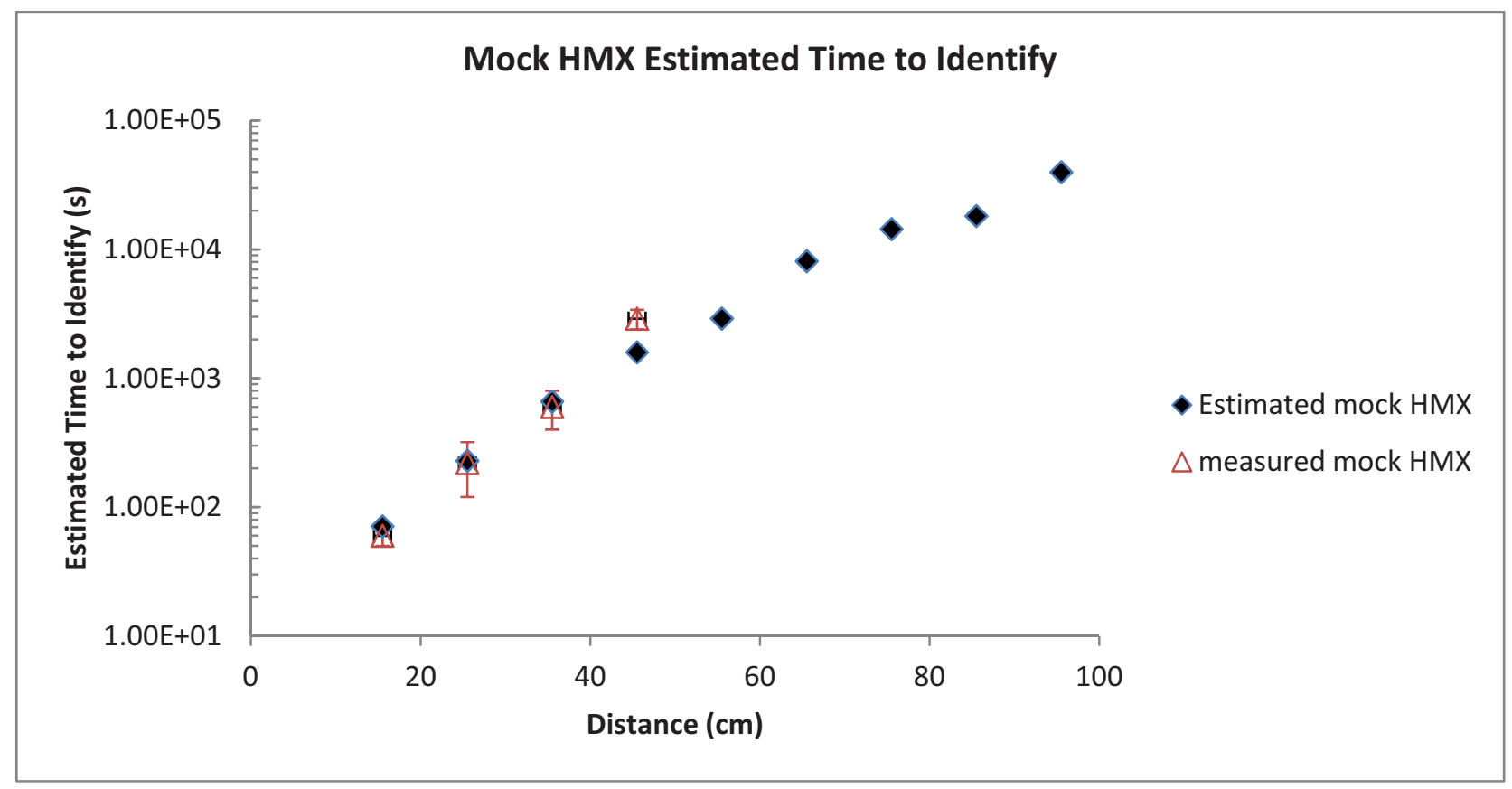

Figure 4 Estimated and measured time to identify mock HMX versus distance 


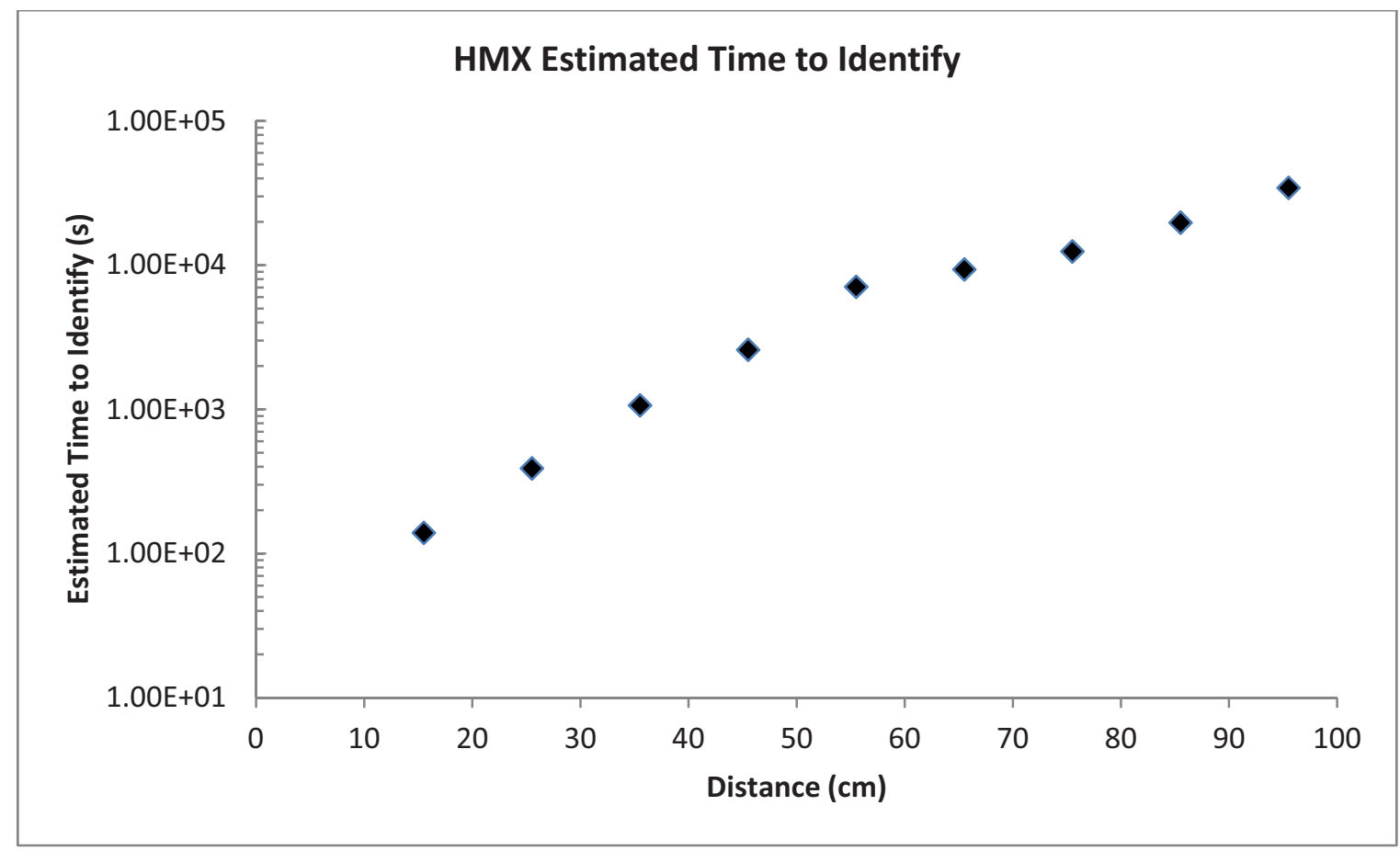

Figure 5 Estimated time to identify HMX

The simulations and measurements described above give a general understanding of the performance of the PINS system in detecting explosives at various standoff distances. The actual numerical results are very specific to the geometries measured and modeled however. The simulations and measurements show that the detection of nitrogen gamma rays falls as a function of the distance to the 2.024 power for distances up to approximately $40 \mathrm{~cm}$. After $40 \mathrm{~cm}$ the nitrogen detection falls off more rapidly.

The estimated time to identify the mock HMX was normalized to the measured times. There is very good agreement between the shapes of the simulated and measured time distributions, which gives confidence in the predicted time estimates for the real HMX. These time estimates indicate that it would take approximately a one hour measurement to detect four kilograms of HMX at $45 \mathrm{~cm}$, three or more hours at $55 \mathrm{~cm}$ and begin to approach a full day measurement time at a one meter standoff distance. The PINS system identifies explosives more quickly at closer distances, with four kilograms of mock HMX being identified in less than an hour at distances less than approximately $40 \mathrm{~cm}$. The typical standoff distance for PINS is closest to the $15 \mathrm{~cm}$ distance where the identification time was less than 200 seconds. 